\title{
A CLINICAL STUDY ON MANAGEMENT OF CORNEAL NEOVASCULARISATION TO PREVENT CORNEAL TRANSPLANT FAILURE
}

\author{
Niraimozhi Raman1, Helen Rosita Gnanaselvan²
}

${ }^{1}$ Assistant Professor, Department of Ophthalmology, KAPV Government Medical College, Trichy. ${ }^{2}$ Assistant Professor, Department of Ophthalmology, KAPV Government Medical College, Trichy.

\section{ABSTRACT}

\section{BACKGROUND}

When it comes to corneal transplant failure, major concern is rejection. Rejection is the main reason for graft failure and neovascularisation is a predictable risk factor for rejection.

\section{MATERIALS AND METHODS}

This study was conducted at Mahatma Gandhi Memorial Govt. Hospital and KAPV. Govt. Medical College, Trichy. About 40 (Forty) patients with corneal neovascularisation due to various corneal diseases from March-2016 to August-2016 were evaluated.

\section{RESULTS}

In our study out of 40 patients, Male cases were $28(70 \%)$ and Female cases were $12(30 \%)$. In the age group of 10 to 30 years there were 12 patients, in 31 to 50 years-14 patients, and in 51 to 70 years-14 patients. We noted significant regression in 20 $(50 \%)$, partial regression in $12(30 \%)$ and no regression in $8(20 \%)$. Subconjunctival bevacizumab was a safer drug and well tolerated by all the patients.

\section{CONCLUSION}

Subconjunctival bevacizumab can be used safely and effectively for corneal neovascularisation from different types of corneal disorders.

\section{KEYWORDS}

Corneal, Bevacizumab, New Vessel, Subconjunctival, Regression.

HOW TO CITE THIS ARTICLE: Raman N, Gnanaselvan HR. A clinical study on management of corneal neovascularisation to prevent corneal transplant failure. J. Evolution Med. Dent. Sci. 2017;6(13):1019-1024, DOI: 10.14260/Jemds/2017/218

\section{BACKGROUND}

The cornea has the unique feature of being normally avascular except for small loops which invade the periphery for about $1 \mathrm{~mm}$. But under pathologic conditions vessels invade the cornea from the limbal vascular plexus resulting in a wide variety of insults including:

- Infection,

- Inflammation,

- Ischaemia,

- Degeneration,

- Trauma and

- Loss of the limbal stem cell barrier which can cause corneal neovascularisation although corneal NV can occasionally serve a beneficial role in the clearing of infections, wound healing, and in arresting stromal melts, its disadvantages are numerous.

Corneal NV often leads to tissue scarring, oedema, lipid deposition, and persistent inflammation that may significantly alter visual acuity. Corneal NV accompanies the

Financial or Other, Competing Interest: None.

Submission 05-01-2017, Peer Review 30-01-2017,

Acceptance 04-02-2017, Published 13-02-2017.

Corresponding Author:

Dr. Niraimozhi Raman

Assistant Professor,

Department of Ophthalmology,

C-5, Teaching Staff Quarters,

KAPV Govt. Medical College,

Periyamilaguparai, Trichy-620001.

E-mail: nirai.opth@gmail.com

DOI: $10.14260 /$ jemds $/ 2017 / 218$

(c) $(7)$ most common causes of corneal infectious blindness in both developed (Herpetic keratitis) and developing (Trachoma and onchocerciasis) worlds, which cause millions to lose their sight.

Neovascularisation (NV) is divided into two main processes; Vasculogenesis and Angiogenesis. The former vasculogenesis is the formation of new blood vessels from bone marrow derived angioblast, while the latter is formation of new blood vessels from already present vascular structures.

Corneal NV may not only reduce visual acuity but also it results in the loss of the immune privilege of the cornea, thereby worsening the prognosis of subsequent penetrating keratoplasty (PK). Pre-existing corneal stromal blood vessels have been identified as a strong risk factor for immune rejection after corneal transplantation. Although various compounds have been shown to inhibit corneal neovascularisation in experimental and clinical situations including steroids, indomethacin, cyclosporine, methotrexate, low molecular weight heparin sulphate, rapamycin and thalidomide, there is still no clear consensus about the best treatment of corneal neovascularisation. Although steroids are the mainstay of treatment in corneal neovascularisation, they are not always effective and without complications.

\section{VEGF in Human Corneal Tissue}

Philipp et al have shown that VEGF is expressed in all three layers of inflamed cornea, including the epithelium, stroma, and endothelium. It is highly expressed in the vascular endothelial cells of limbal vessels and in newly formed vessels in the stroma and weakly in keratocytes. Therefore, 
subconjunctival injection route will be better for the access of medication to limbal endothelial cells.

\section{Rationale for Angiogenesis Inhibitors in Corneal Neovascularisation}

Animal studies have supported the role of VEGF in the pathogenesis of corneal neovascularisation. In expermental models, increased levels of VEGF mRNA and protein and VEGF receptors have been demonstrated in corneal neovascularisation. Human corneal buttons with new vessels have been shown to have higher levels of VEGF and its receptors. VEGF inhibition therefore supresses corneal neovascularisation and helps improve vision or increase the chance of transplant survival.

\section{An update on Bevacizumab}

Bevacizumab (Avastin, Genentech) is a full length humanised murine monoclonal antibody, directed against all the biologically active forms of VEGF- A. Bevacizumab, the first anti- VEGF drug to be approved by the FDA was developed as an intravenous therapy for cancer patients, because VEGF is one of the major angiogenic stimuli, responsible for neovascularisation in tumours. ${ }^{1}$ In clinical trials, the most common adverse event caused by bevacizumab was hypertension.2,1 Bevacizumab has now been widely adopted and is arguably part of the standard of care for the treatment of neovascular AMD for many patients. ${ }^{1}$

\section{Pharmacokinetics of subconjunctivally Administered Bevacizumab}

In general, drug is injected into subconjunctival space by two methods: direct trans-scleral delivery into intraocular tissues or clearance via conjunctival blood and lymphatic flow. Since IgG has a relatively high scleral permeability and has the same molecular weight as bevacizumab, some of the bevacizumab injected into the subconjunctival space may penetrate intraocular tissues including the retina/choroid, iris/ciliary body, and vitreous via the sclera. The bevacizumab level in the retina/choroid and iris/ciliary body was maintained above $\mathrm{IC}_{50}$ for 8.6 and 8.4 weeks, respectively, whereas it was maintained above $500 \mathrm{ng} / \mathrm{mL}$ for 0.3 weeks in the iris/ciliary body. The sclera consists of collagen and elastin chains that create a fibre matrix in which the pore diameter and intracellular space may determine the permeability of drugs. Negatively charged drugs have been found to have higher permeability than those with positive charges in bovine and porcine sclera. Proteoglycans in the sclera are negatively charged, which may contribute to the binding of positively charged molecules. An isoelectric point of bevacizumab has been found to be approximately 8.4 . Therefore, longer $T_{1 / 2}$ in the iris/ciliary body and retina/choroid after subconjunctival injection compared with those after intravitreal injection may sustain bevacizumab delivery into intraocular tissues due to scleral depot binding of bevacizumab to the scleral matrix.

Since the conjunctival blood vessels do not form a tight junction barrier, bevacizumab can enter into the blood circulation by pinocytosis and/or convective transport through paracellular pores in the vascular endothelial layer. The Fc receptor, which binds to both albumin and the Fc portion of IgG, was detected in the lymphatic vessels but not in the blood vessels of the conjunctiva. It may be that the function of the Fc receptor in the conjunctival lymphatic vessels is to act as an efflux receptor for the efficient elimination from the conjunctival space. Residual bevacizumab, other than the bevacizumab that directly permeated the sclera and was introduced into the blood circulation, may be eliminated from the conjunctival tissue into the lymphatic vessels via convective transport with lymphatic fluid.

Systemic exposure of bevacizumab when administered by intravitreal and subconjunctival injection was very similar. Bevacizumab was detected in the fellow eye treated by intravitreal or subconjunctival injection. Bevacizumab may have been transported through the systemic circulation into the fellow eye. In the fellow eye treated by intravitreal injection, bevacizumab concentration in the retina/choroid was maintained above $\mathrm{IC}_{50}$ for 8.0 weeks.

Heiduschka et al demonstrated that bevacizumab can penetrate the retina and is transported into the retinal pigment epithelium, choroid, and photoreceptors after intravitreal injection using an immunohistochemical staining assay with donkey anti-human IgG. In that study, the antibody used for the detection of bevacizumab recognised the injected bevacizumab molecule specifically. ${ }^{3}$

The strong intracorneal bevacizumab staining could persist for at least 3 days in the VEGF micropocket and alkaliinduced corneal NV models after a single subconjunctival injection. The distribution of intracorneal bevacizumab could persist at least up to 7 days in the normal corneas. The reason for the different durations of intracorneal diffusion remains to be evaluated. Although not proven, the shorter duration of bevacizumab distribution in the vascularised corneas may be caused by the rapid absorption through the corneal vessels. In some studies, the eyes treated with bevacizumab showed significant decrease in the amount of neovascularisation especially those treated with subconjunctival bevacizumab..$^{4,5}$

\section{Side Effects of Subconjunctivally Administered Bevacizumab Systemic}

There are several reports that have noted the systemic adverse effects of bevacizumab after intravitreal injection. These adverse effects are similar to the ones reported for intravenous administration of bevacizumab for cancer treatment, such as systemic hypertension, thromboembolic diseases and death. In addition, Shima et al found irregular vaginal bleeding as a complication in young women receiving intravitreal injection of bevacizumab. It should be noted, however, that these were small studies with a small amount of participants. Systemic adverse effects of bevacizumab may occur after subconjunctival injection, as well as after intravitreal or intravenous injection. Therefore, intravitreal or subconjunctival bevacizumab should be used with caution in elderly patients with choroidal or iris neovascularisation. However, efficacy in the fellow eye should be expected to derive from the systemic circulation.

\section{Ocular}

Corneal epithelial defect, corneal ulcer, corneal oedema, conjunctival necrosis, anterior uveitis, and infectious endophthalmitis. 


\section{MATERIALS AND METHODS}

This study was done in Mahatma Gandhi Memorial Govt. Hospital and KAPV Govt. Medical College, Tiruchirapalli during March 2016 to August 2016.

Forty eyes of forty patients with corneal neovascularisation due to various pathologies (mentioned below) have been selected for the study.

\section{Study Design}

- Interventional.

- Prospective.

- Non-randomised clinical study.

\section{Inclusion Criteria}

Vascularised Corneas of Patients with-

- Leucomatous opacity following exanthematous fever and post hydrops.

- Pseudophakic bullous keratopathy.

- Healed corneal ulcer post-trauma and infection.

- Previously failed optical keratoplasty.

\section{Exclusion Criteria}

- Patients with uncontrolled systemic hypertension with systolic blood pressure of $\geq 150 \mathrm{mmHg}$ or diastolic blood pressure of $\geq 90 \mathrm{mmHg}$.

- Patients with recent myocardial infarction.

- Patients with recent cerebrovascular accidents.

- Diabetes mellitus.

- Renal, liver, and coagulation abnormalities including current anticoagulation medications.

- Current or recent systemic corticosteroid therapy or periocular corticosteroid injections to the study eye.

- Ocular or periocular malignancy.

- Pregnancy, lactating women, postmenopausal women not using adequate contraception.

- Any condition that precluded patient's ability to comply with study requirements including completion of study.

\section{Procedure}

Patients who were referred to cornea clinic with corneal neovascularisation (mentioned above in inclusion criteria) were selected for the study.

A brief history of all the patients were taken and subjected to detailed ocular and systemic examination.

Anterior segment examination was done with slit-lamp biomicroscopy. Standardised corneal photographs were taken with 10X magnification with slit-lamp biomicroscopy using digital camera.

The off-label use of the drug and its benefits were discussed with all the patients. Informed consent was obtained. Detailed corneal drawings were done.

\section{Number of Patients}

Twenty eyes of twenty patients with corneal neovascularisation due to various pathologies (mentioned above) have been selected for the study.

- Ten eyes of 10 patients with healed fungal corneal ulcer.

- Four eyes of 4 patients with leucomatous opacity postexanthematous fever.

- Fourteen eyes of 14 patients with pseudophakic bullous keratopathy.
- Six eyes of 6 patients with previous failed keratoplasty due to vascularisation.

- Two eyes with post hydrops (keratoglobus).

- Four eyes of 4 patients with post-traumatic leucomatous opacity.

The off-label use of the drug and its potential risks and benefits were discussed extensively with all patients. All patients signed a comprehensive consent form before administration of the subconjunctival injection of bevacizumab.

A commercially available bevacizumab $(2.5 \mathrm{mg} / 0.1 \mathrm{~mL}$, $100 \mathrm{mg} / 4 \mathrm{~mL}$ ) was prepared for each patient and placed in a tuberculin syringe using aseptic techniques-

- Topical anaesthetics (4\% Xylocaine/Paracaine eye drops) and antibiotics are applied.

- The eye had been prepared with $5 \%$ povidone iodine in a standard fashion.

- Then draped with an eye mask.

- Opsite was applied.

- Using lid speculum eye was exposed.

- Bevacizumab (2.5 mg/0.1 $\mathrm{mL})$ was injected subconjunctivally in the quadrant of vascularisation $1 \mathrm{~cm}$ from the limbus.

- Patients were instructed to apply antibiotic eye drops for 3 days 4 times a day.

\section{Follow-Up}

Follow-up visits were done on $14^{\text {th }}$ day, $1^{\text {st }}, 3^{\text {rd }}$, \& $6^{\text {th }}$ month post-injection. All the 40 patients completed 6 months of follow-up. At each visit, patients were checked for regression of new vessels i.e. reduction in both number and calibre of the vessel.

\section{Main Outcome Measures}

i. Regression of corneal new vessels.

ii. Efficacy and safety of subconjunctival bevacizumab.

\section{RESULTS}

In our study, the upper age limit being 70 years and lower age limit being 15 years. The mean age was 42 years.

\begin{tabular}{|c|c|c|}
\hline Age Distribution & No. of Patients & Percentage (\%) \\
\hline $10-30$ Years & 12 & 30 \\
\hline $31-50$ Years & 14 & 35 \\
\hline $51-70$ Years & 14 & 35 \\
\hline \multicolumn{2}{|c|}{ Table 1. Age Distribution } \\
\hline
\end{tabular}

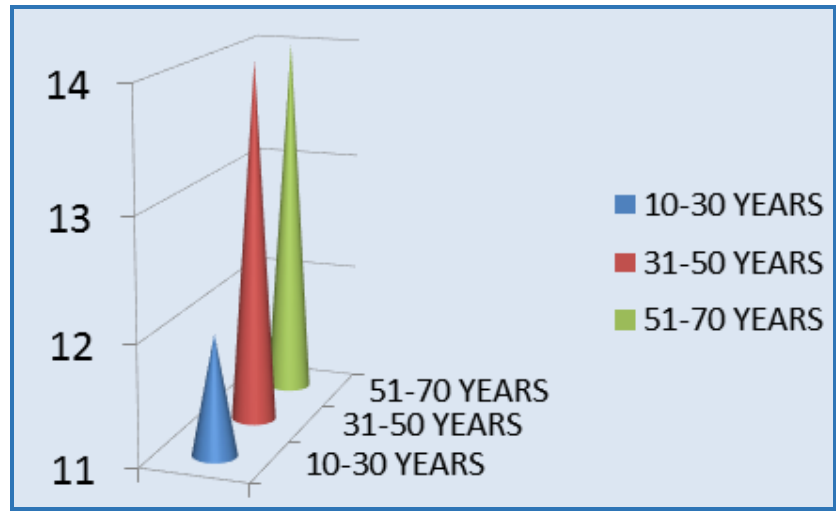

Figure 1. Age Distribution 
Of the 40 patients who met the inclusion criteria for the study, 28 were male and 12 were female.

\begin{tabular}{|c|c|c|}
\hline Sex & No. of Patients & Percentage (\%) \\
\hline Male & 28 & 70 \\
\hline Female & 12 & 30 \\
\hline \multicolumn{2}{|c|}{ Table 2. Sex Distribution } \\
\hline
\end{tabular}

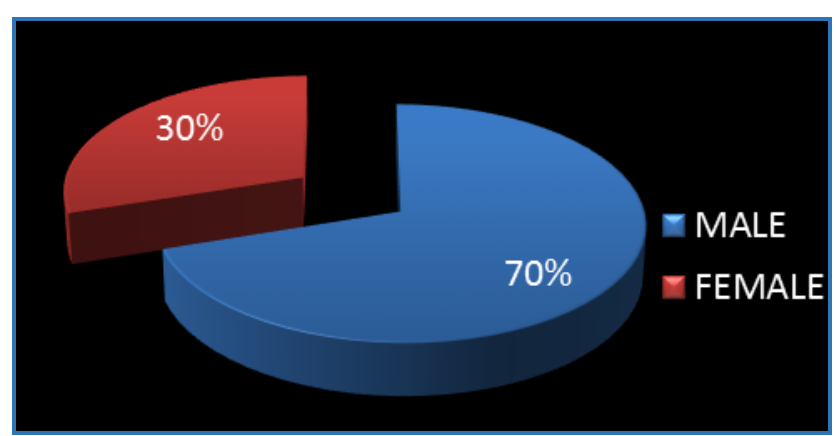

Figure 2. Male: Female Ratio $\approx 2.3: 1$

\section{Causes for Corneal Neovascularisation}

\begin{tabular}{|c|c|c|}
\hline Indications & $\begin{array}{c}\text { No. of } \\
\text { Patients }\end{array}$ & (\%) \\
\hline Healed Fungal Corneal Ulcer & 10 & 25 \\
\hline $\begin{array}{c}\text { Leucomatous Opacity- } \\
\text { Post exanthematous Fever }\end{array}$ & 6 & 15 \\
\hline Pseudophakic Bullous Keratopathy & 12 & 30 \\
\hline Previously Failed OKP for Regraft & 6 & 15 \\
\hline Post Hydrops-Keratoglobus & 2 & 5 \\
\hline Post Traumatic Leucomatous Opacity & 4 & 10 \\
\hline \multicolumn{3}{|l|}{ Table 3. Indications } \\
\hline
\end{tabular}

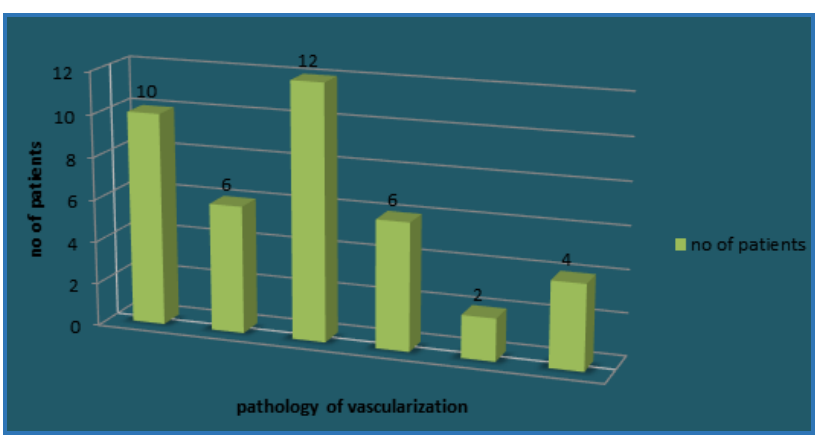

Figure 3. Indications

Main Outcome Measures

The regression of corneal new vessels occurred to a different degree in each patient.

\begin{tabular}{|c|c|c|}
\hline Regression & No. of Patients & Percentage (\%) \\
\hline Complete Regression & 20 & 50 \\
\hline Partial Regression & 12 & 30 \\
\hline No Regression & 8 & 20 \\
\hline
\end{tabular}

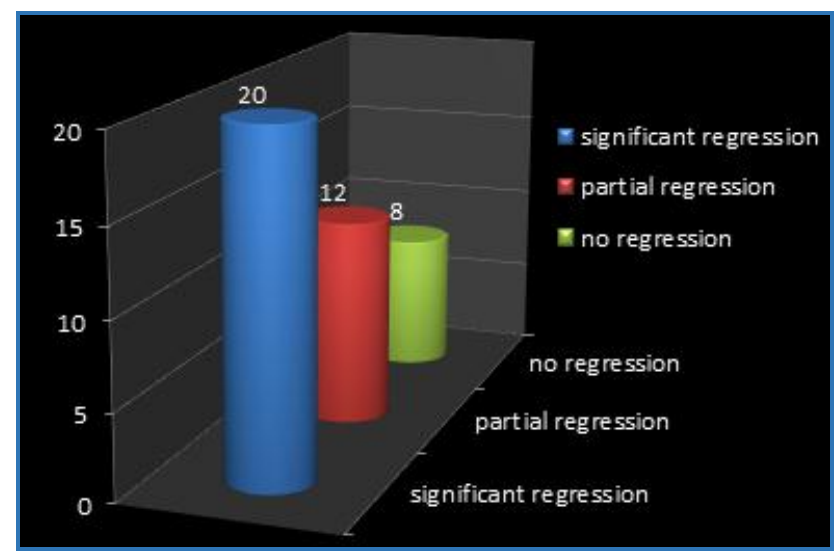

Figure 4. Percentage of Regression of Corneal New Vessels

Complete Regression

$50 \%$ of patients showed almost complete regression of the new vessels at the end of 6 months.

\section{Leucomatous Opacity with Neovascularisation}

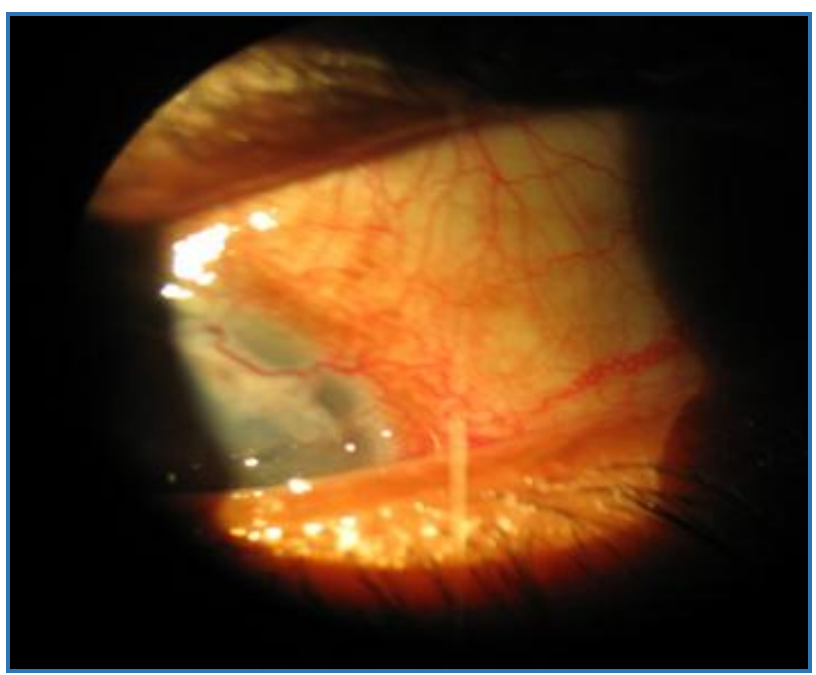

Figure 5. Pre -injection

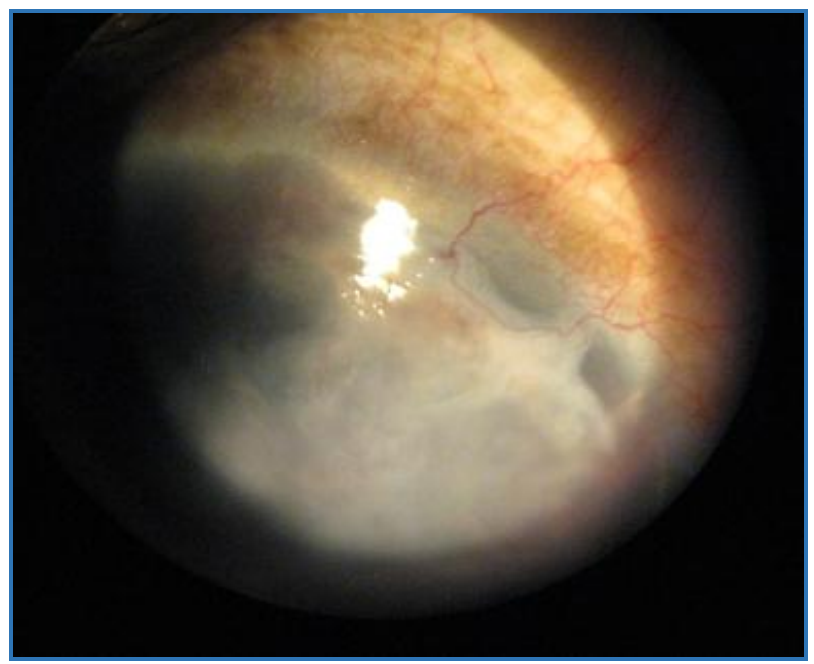

Figure 6. 2 Weeks Post-injection 


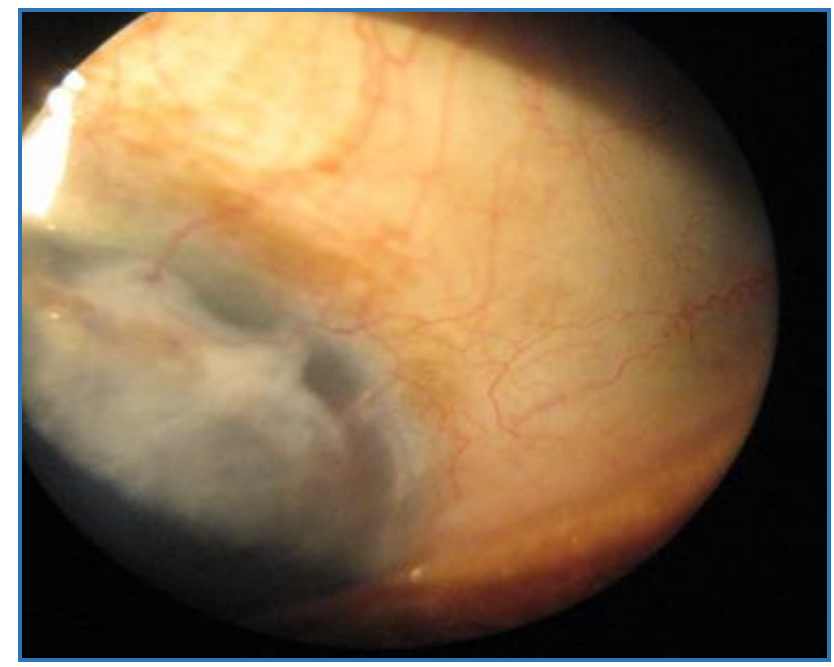

Figure 7. 1 Month

Post-injection

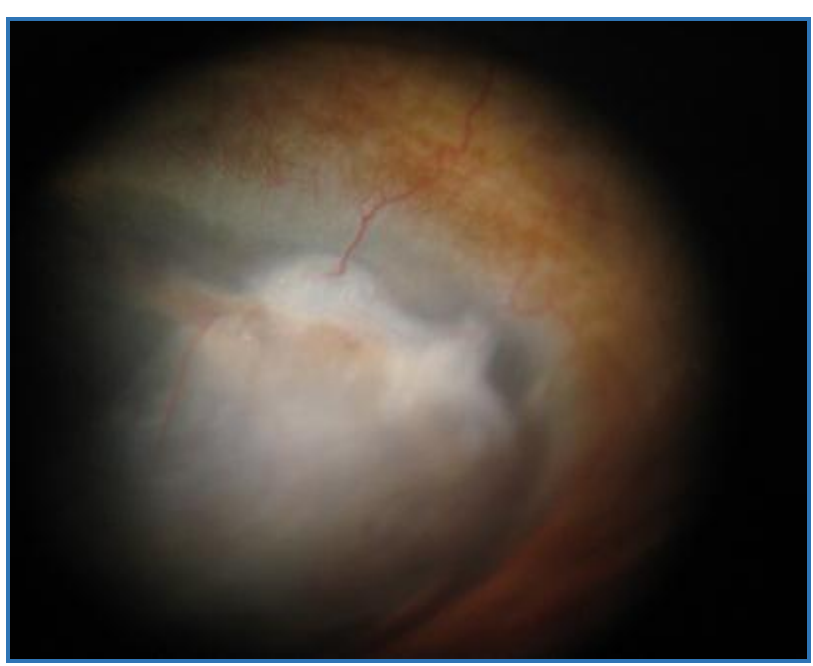

Figure 8. 3rd Month

Post-injection

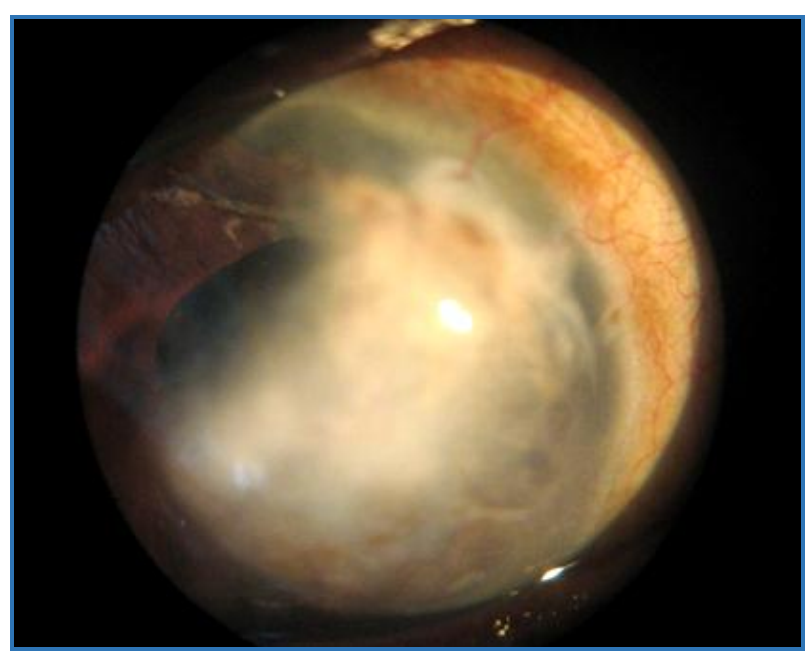

Figure 9. $6^{\text {th }}$ Month

Post-injection

\section{Partial Regression}

$30 \%$ of the patients showed partial regression.

\section{Post Traumatic Leucomatous Opacity}

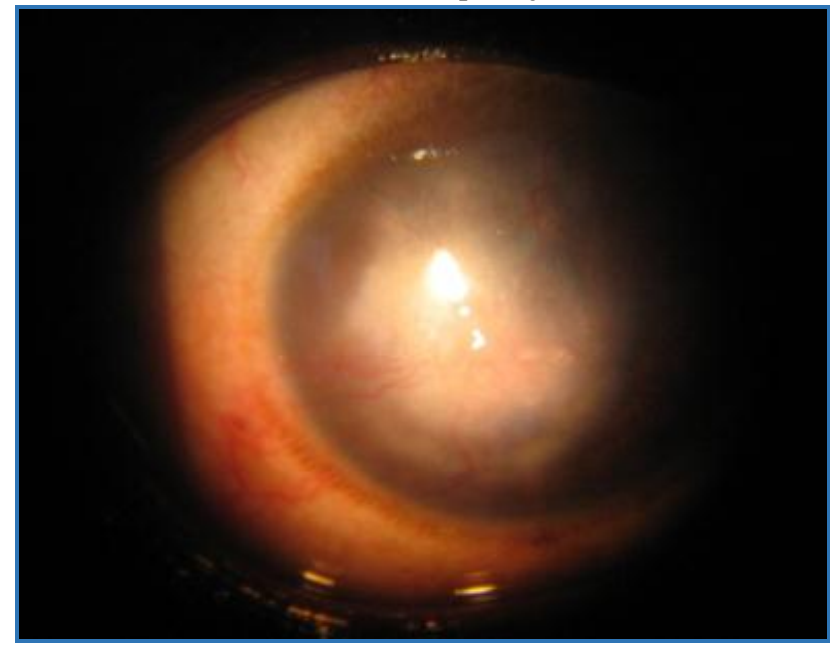

Figure 10. Pre-injection

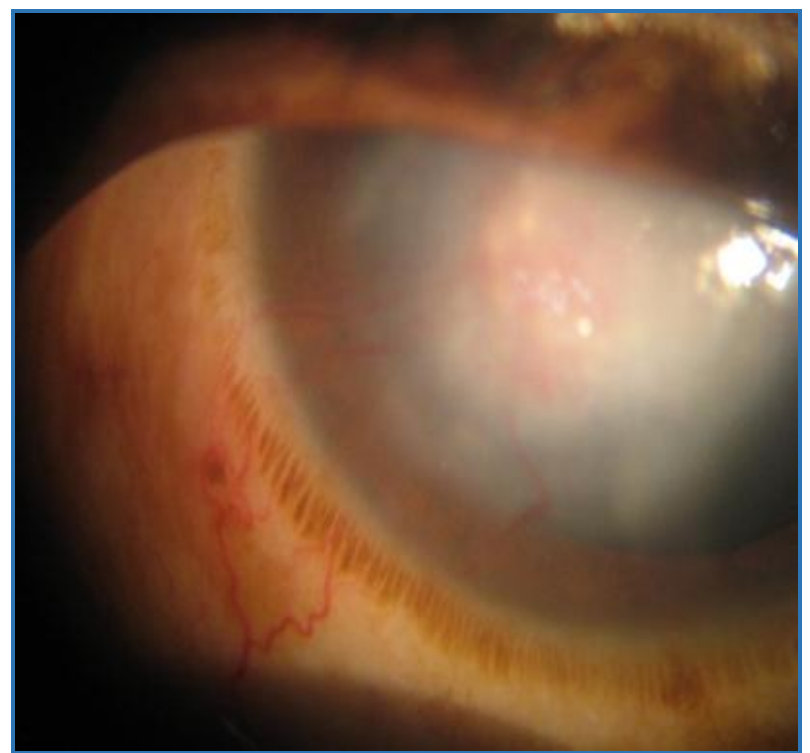

Figure 11. 3 Months Post-injection

\section{No Regression}

$20 \%$ of the patients showed No Regression at end of 6 months.

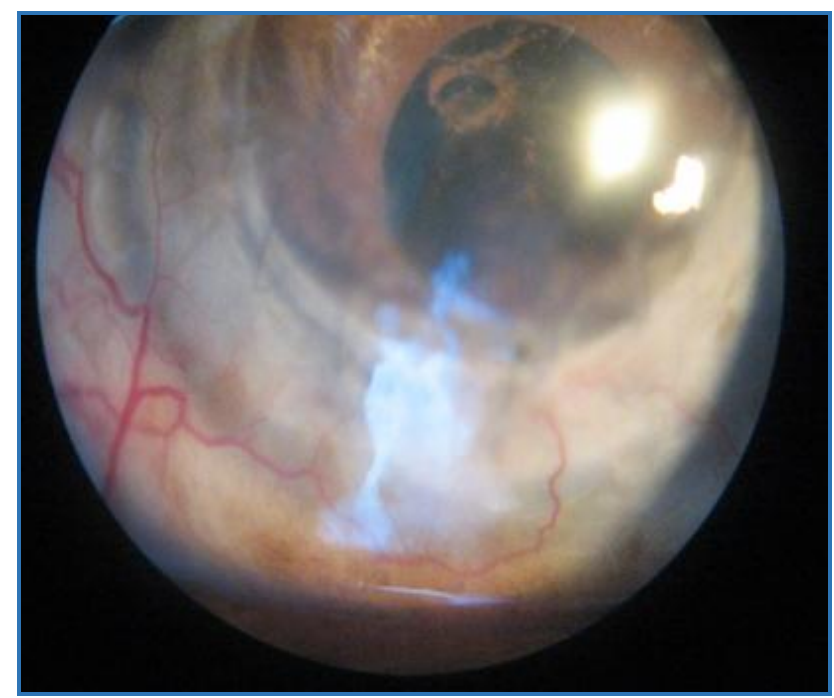

Figure 12. 2 Months Post-injection 


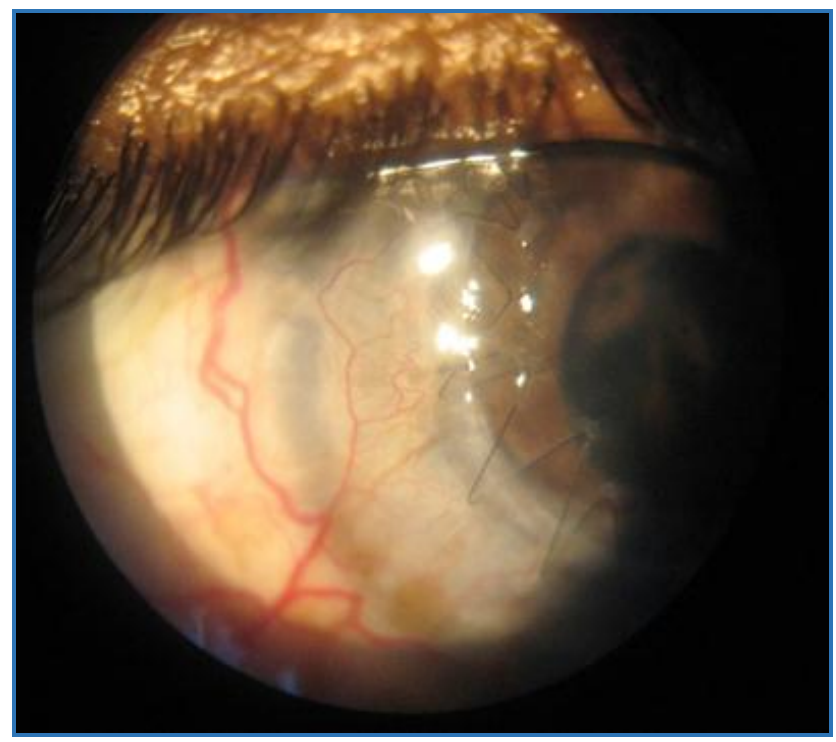

Figure 13. 6 Months Post-injection

\section{DISCUSSION}

Corneal neovascularisation remains a significant risk factor for corneal transplantation and subsequent graft failure after transplantation. The collaborative corneal transplantation study identified, in addition to several other factors, the extent of stromal vessel (Quadrants) involvement as a strong risk factor for corneal graft failure.

Various medications and surgical therapies have been attempted to reduce corneal angiogenesis including corticosteroids, non-steroidal anti-inflammatory drugs, laser photocoagulation and needle diathermy. Many of these therapies are associated with adverse effects and risks, and most of these therapies have demonstrated limited success. Furthermore, none of these treatments specifically target the inhibition of VEGF.6,7

Anti-VEGF therapy, used to reduce corneal angiogenesis, has recently granted interest based on the successful results demonstrated with intravitreal bevacizumab. Preliminary in vivo animal data have shown the potential effectiveness of bevacizumab in treating corneal neovascularisation.

This is a 6-month prospective, non-randomised clinical study to investigate the safety and efficacy of intravitreal bevacizumab for the treatment of corneal neovascularisation.

In this study, an obvious reduction in established corneal neovascularisation occurred to a different degree in each patient, and subconjunctival bevacizumab was well tolerated by all these patients. Out of 40 patients in $50 \%$ of patients, complete regression of the corneal new vessels noted at the end of $6^{\text {th }}$ month. Whereas in $30 \%$ of patients only partial reduction noted i.e. reduction in calibre of vessels only, the number of new vessels was constant. In $20 \%$ of patients, both number of new vessels and the calibre was constant.
This variable response may be because of the chronicity, extent of corneal neovascularisation, amount of scarring, disease process, formulation and route of administration of the drug. ${ }^{7}$

Successful reduction of corneal neovascularisation with subconjunctival anti-VEGF therapy could play an important role in improving graft survival in patients who have preexisting corneal neovascularisation (NV) or NV of the peripheral cornea that develops after penetrating keratoplasty. The reduction or elimination of corneal NV could therefore allow for corneal transplantation in those patients who were previously considered high risk and had contraindication to surgery.

\section{CONCLUSION}

- Subconjunctival injection of bevacizumab can be used safely and effectively for corneal neovascularisation resulting from different types of disorders.

- It may provide an additional strategy in improving success of corneal grafts in these patients.

- This is a short-term study. However, long-term follow-up is necessary to determine whether repeat injections are necessary.

\section{REFERENCES}

[1] Dastjerdi MH, Al-Arfaj KM, Nallasamy N, et al. Topical bevacizumab in the treatment of corneal neovascularisation: results of a prospective, openlabel, noncomparative study. Archives ophthalmology 2009;127(4):381-9.

[2] Ferrara N. Vascular endothelial growth factor: basic science and clinical progress. Endocrine Rev 2004;25(4):581-611.

[3] Chang JH, Gabison EE, Kato T, et al. Corneal neovascularisation. Curr Opin Ophthalmology 2001;12(4):242-9.

[4] Dana MR, Streilein JW. Loss and restoration of immune privilege in eyes with corneal neovascularisation. Invest Ophthalmology Vis Sci 1996;37(12):2485-94.

[5] Dawson DW, Volpert OV, Gillis P, et al. Pigment epithelium-derived factor: a potent inhibitor of angiogenesis. Science 1999;285(5425):245-8.

[6] Simon JW, Ngo Y, Khan S, et al. Surgical confusions in ophthalmology. Archives ophthalmology 2007;125(11):1515-22.

[7] Zaki AA, Fouad H, Emera S, et al. Subconjunctival anti VEGF for conjunctival intraepithelial and invasive neoplasia. Australian journal of basic and applied sciences 2009;3(4):3186-9. 